\title{
A escola e o sonhar: espaço de motivação e aprendizagem
}

\section{The School and dreaming: space for motivation and learning}

\author{
Manoel Domingos Castro Oliveira*, Antônio Flávio Costa Pinheiro**, Maria José Marques Lima**, Maria Flávia \\ Coelho Albuquerque**, Maria de Lourdes Benevides de Magalhães**, Aparecida Alves dos Santos Coelho***, Cláudia \\ Machado****,Gesilane Domingos de Sousa*****,Cláudia Maria Sales Mendes******, Fabiana Lima Abreu*******, \\ Jorge Fernandes Barbara*******
}

\begin{abstract}
*Universidade de Trás os Montes e Alto Douro, **Universidade Federal do Ceará, ***Universidade Federal da Paraíba, ****Universidade de Aveiro, *****Universidade Estadual do Ceará, ******Universidade do Minho, *******Instituto Federal de Educação, Ciência e Tecnologia do Ceará,********Instituto Árvore da Vida
\end{abstract}

\begin{abstract}
Resumo
Esse trabalho tem como objetivo mostrar o processo de reorganização curricular no Ceará através da experiência inovadora do Núcleo de Trabalho, Pesquisa e Práticas Sociais (NTPPS), que está sendo implementado no ensino médio de escolas públicas do Estado, através da Secretaria de Educação do Estado do Ceará (SEDUC), e que vem fortalecendo o aprendizado direcionado ao desenvolvimento de pesquisas, mas também trabalha as competências socioemocionais dos alunos, o autoconhecimento, o protagonismo, a sua relação com a família e a vida em sociedade. A metodología utilizada foi de natureza qualitativa, onde os métodos aplicados são a entrevista e a observação.
\end{abstract}

Palavras-chave: competências socioemocionais, reorganização curricular, protagonismo

\begin{abstract}
This work aims to show the process of curricular reorganization in Ceará through the innovative experience of the Center for Work, Research and Social Practices (NTPPS), which is being implemented in the high school of public schools of the State, through the State Education Secretariat Of Ceará (SEDUC), and that has been strengthening the learning directed to the development of research, but also works the students' social-emotional competences, self-knowledge, protagonism, their relationship with family and life in society. The methodology used was of a qualitative nature, where the applied methods are interview and observation.

Keywords: socio-emotional competencies, curricular reorganization, protagonismo.
\end{abstract}

Uma educação que se pauta na divisão exacerbada do conhecimento, uma hora mostraria cansaço e falência. $\mathrm{O}$ ritmo como as coisas acontecem no mundo hoje, com a globalização das informações, parece que é umadisparidade com o que acontece dentro dos ambientes escolares, com currículos ultrapassados e uma imensidão de conteúdos desconectados que dificultam o aprendizado do aluno. No Brasil, as avaliações educacionais em larga escala, como o Índice de Desenvolvimento da Educação Básica (IDEB), o Sistema
Permanente de Avaliação da Educação Básica do Ceará (SPAECE) e o Exame Nacional doEnsino Médio (ENEM), como também as internacionais como o PISA (Programa Internacional de Avaliação de Estudantes) mostram uma constante queda dos índices, o que revela que algo precisa ser revisto, reavaliado e mudado.

Mais exercícios, mais repetição e mais testes podem até resultar em uma nota maior, mas não prepararão o aluno de forma integral e, muito menos, darão conta de desenvolver todas as competências que ele necessita para enfrentar os desafios do século 21. Enquanto o mundo abre espaço e cobra que os jovens sejam protagonistas de seu próprio desenvolvimento e de suas comunidades, o ensino tradicional ainda responde com modelos criados para atender demandas antigas (Porvir, 2015).

Busca-se, no mundo todo, uma educação que seja mais flexível e abrangente. E é nesse cenário que a inserção das competências socioemocionais é hoje trabalhada na educação de vários países como Canadá, Colômbia, Estados Unidos e Brasil.A Organização das Nações Unidas para Educação Ciência e Cultura (UNESCO), em 2010, lança o relatório que sugere um ensino baseado em quatro pilares: aprender a conhecer, aprender a fazer, aprender a conviver e aprender a ser. Assim o indivíduo aprende ao longo da vida a estudar com desempenho um número reduzido de assuntos, estando disposto a enfrentar diferentes tipos de situações e a trabalhar em equipe, gerenciando conflitos, e tendo condições crescentes de agir com autonomia, discernimento e responsabilidade pessoal.

\footnotetext{
A socialização de cada indivíduo e o desenvolvimento pessoal não devem ser excludentes; torna-se necessário promover um sistema que se empenhe em combinar as vantagens da integração com o respeito pelos direitos individuais. A educação não pode, por si só, resolver os problemas desencadeados pela ruptura (quando se verifica tal ocorrência) do vínculo social; no entanto existe a expectativa de que ela contribua para o desenvolvimento do desejo de conviver, elemento básico da coesão social e da identidade nacional. (Unesco, 2010).
} 
O Instituto Ayrton Senna que é uma organização sem fins lucrativos atua em parceria com profissionais da educação, pesquisadores de diversas áreas do conhecimento e demais atores sociais para transformar a realidade de crianças e adolescentes por meio da educação. Defende a proposta de educação integral para o ensino médio, abordando a relação que existe entre desenvolvimento socioemocional e desenvolvimento cognitivo bem como o elo desses dois com os ambientes de aprendizagem como a escola, a família, a comunidade, o ambiente de trabalho e etc.

A formação para a autonomia se faz por meio do desenvolvimento de competências que combinem aspectos cognitivos e socioemocionais, possibilitando aos estudantes se capacitarem para o autoconhecimento, a colaboração, a criatividade, a resolução de problemas, o pensamento crítico, a abertura para o novo e a responsabilidade no alcance de seus objetivos. (Instituto Ayrton Senna, 2017).

Essa educação integral poderia ser uma luz no fïm do túnel para a educação? A resposta não é simples e nem clara no momento. Busca-se há anos entender o que acontece com a educação e que caminhos seguir para se alcançar melhores resultados nas avaliações educacionais do Brasil, já citadas no início desse texto, mas, fundamentalmente, objetiva-se transformar a vida de muitos jovens. E para isso é importante que a inclusão dessas competências socioemocionais na educação seja algo intencional, ou seja, é preciso ser algo planejado, executado e acompanhado.

No Ceará, já faz cinco anos de uma experiência inovadora na educação, através do Núcleo de Trabalho, Pesquisa e Práticas Sociais (NTPPS), conhecido apenas como Núcleo, e que desenvolve o aprendizado direcionado ao desenvolvimento de pesquisas, mas também trabalha as competências socioemocionais dos alunos, o autoconhecimento, a sua relação com a família e sua vida em sociedade.

O NTPPS tem como objetivo trabalhar o indivíduo em sua integralidade, favorecendo o autoconhecimento de suas competências e habilidades, desenvolvendo a pesquisa científica articulada com todas as áreas do conhecimento, fortalecendo a autonomia para traçar seu projeto de vida. (Material de referência do Seminário Internacional Competências para a Vida: onde estamos e aonde queremos chegar, 2017).

\section{É preciso sonhar para aprender diferente}

O Núcleo foi criado em 2012, através da parceria Instituto Aliança (IA) / Secretaria de Educação do Estado do Ceará (SEDUC) com forte inspiração, tanto nas Diretrizes Curriculares Nacionais para o Ensino Médio quanto nos protótipos curriculares para o Ensino Médio, lançados pela representação da UNESCO no Brasil.

Quando surgiu a ideia de o Núcleo ser implementado nas escolas, foi bastante questionado, quer seja pela necessidade de uma maior carga horária para os alunos,

quer seja pela dúvida da sua real significância no aprendizado. Depois de muitas reuniões e capacitações de professores, a proposta do Instituto Aliança, acolhida pela Secretaria de Educação do Ceará (SEDUC), começa a acontecer, inicialmente, em 12 escolas da rede de ensino estadual. Hoje, o NTPPS já chega a 160 escolas, sendo 71 de tempo integral.O Núcleo quando foi implantado (...) houve uma votação, a diretora trouxe a proposta para os professores aprovarem ou não, porque iria aumentar a carga horária e o horário de término da aula também porque passaria a ter seis aulas. A princípio o que foi que todo mundo pensou e foi um pensamento meu também, 'isso é mais um projeto (...) que vem, a gente começa e depois é esquecido'. Quando a professora I.N foi para o Núcleo eu pensei 'ela é doida' (...) Depois, assim, eu senti o envolvimento das professoras de Núcleo e senti a rejeição dos demais professores, no início foi dificílimo. Muitos professores não queriam se quer ouvir. Enfim, no começo tudo muito novo, tudo muito difícil. Eu não botava muita fé não. Eu achava que os alunos não iam se envolver e aquilo ali ia ficar por isso. Hoje eu tenho uma visão completamente diferente do Núcleo, realmente, porque já está a cinco anos e a gente percebe (...) uma sensível diferença do aluno que saiu do nono ano que não tinha Núcleo para o aluno que chegou na escola, principalmente, nessa questão da formação humana, mas assim, em relação a pensar no projeto de vida, de pensar como grupo e se sentir parte de um grupo, de olhar para sí. A gente começa a ver uma diferença. Eu tive depoimentos de mãe, esse ano, que chegaram para mim dizendo que o filho estava amando, que a coisa que o menino mais gostou na escola foi o Núcleo. Eu acredito que a pesquisa como princípio educativo, ela é extremamente importante, porque a gente entra na universidade verde. (Professora G.C Química).

Para estruturar a proposta do NTPPS na escola, considerou-se dois documentos relevantes: as Novas Diretrizes Curriculares Nacionais para o Ensino Médio (Resolução CNE/CEB no 2, de 30 de janeiro de 2012) e os Protótipos Curriculares para o Ensino Médio (EM), lançados em maio de 2011 pela Representação da UNESCO no Brasil (Unesco, 2011). O intento da implementação do NTPPS foi iniciar uma reorganização curricular no Estado do Ceará. O Núcleo veio como uma ferramenta que iria unir o conhecimento de todas as áreas (Ciências Humanas, Ciências da Natureza, Matemática e Linguagens) através da pesquisa.

\section{Apresentação e análise de dados}

$\mathrm{Na}$ escola, a proposta acontece como oficinas ministradas por um professor, onde os encontros realizam-se duas vezes na semana. Nessas aulas, o aluno desenvolve a oralidade através de apresentações que falam da sua própria vida e da família e depois apresenta também trabalhos científicos.

"No Núcleo você é convidado a se abrir mais, a conversar, a dizer coisas que o professor de matemática e português não lhe perguntam, as vezes não quer saber. A professora do Núcleo deixa esse espaço aberto, ela lhe dar essa oportunidade de você falar isso, de você se abrir com ela. Trazer o que você sente e não consegue dizer em 
casa, não consegue dizer com os amigos" (Aluno M. M. $\mathrm{S}$ aluno $3^{\circ}$ ano $\left.\mathrm{EM}\right)$.

Essas oficinas fortalecem a escrita ao incentivar a elaboração de textos-sentido, desenvolve o gosto pela leitura, uma vez que nessas oficinas são estudados vários textos de excelente compreensão e significância.

"O que mais me chama a atenção é a capacidade deles se colocarem em sala de aula. Antes eles eram muito presos, calados, não participavam e hoje eles participam muito, inclusive tomam a frente e dizem 'Professora, eu aqui, deixa eu ler'. Então a gente percebe muito isso neles, essa mudança. (Professora M.F - Núcleo $1^{\circ}$ e $2^{\circ}$ anos EM). Amplia o cuidado com o outro, a aceitação e respeito às diferenças e revela a necessidade de um projeto de vida para se alcançar as metas traçadas

"Eu aprendi no Núcleo a trabalhar mais em grupo, a aceitar a opinião do outro, a escutar mais, a reivindicar meus direitos porque antes eu nem ligava para isso e hoje eu vejo que (...) a gente tem que ir para a rua e mostrar aquilo que está nos indignando. Nas pesquisas me aprofundei mais em temas que nunca imaginei, que foi a transfobia, a homofobia e outros. (Aluna I.F - $2^{\circ}$ ano EM).

As oficinas, trazem também temas como: projeto de vida, sexualidade, ética, meio ambiente, drogas, dentre outros. Além da relevância desses temas, utiliza-se, nessas oficinas, metodologias diferenciadas na sua execução. São aulas bem dinâmicas, o que as tornam, do ponto de vista de muitos alunos, aulas prazerosas de vivenciar.

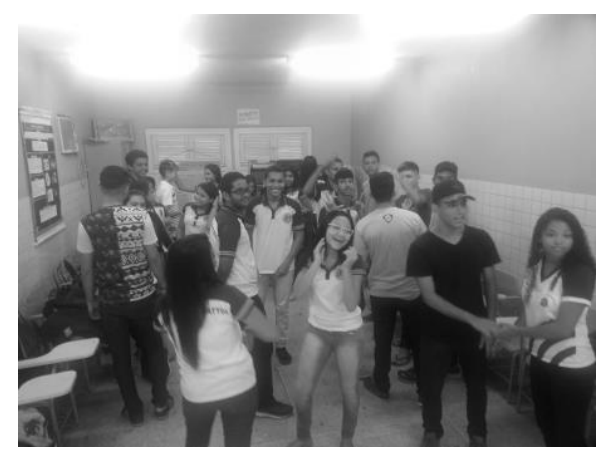

Figura 1.Oficina do NTPPS com aluno do $1^{\circ}$ ano EM. Fonte: autora

"O projeto do Núcleo me incentiva, pessoalmente, a vir para a escola porque é o tipo da coisa, a gente já está tantos anos na escola, vendo as mesmas matérias que chega um ponto que a gente chega a fadigar, chega a cansar um pouco de tanta matemática, física, fórmula, química, números, números, frações e frações e isso cansa. $\mathrm{O}$ Núcleo não, é uma coisa que envolve o aluno, que a pessoa vai lá e vai trabalhar com a mente, eu vou trabalhar com computador, eu vou fazer trabalho de campo. É uma coisa bem interessante que incentiva mesmo" (Aluno A.M.S $2^{\circ}$ ano do EM).

O Núcleo trabalha com metodologias participativas que estimulam o protagonismo e a autonomia dos jovens; foca na formação integral do jovem, envolvendo os quatro pilares da educação: aprender a ser, a conviver, a fazer e a conhecer, cujos eixos são o Fortalecimento da Identidade e Projetos de Vida (Nobre, 2015).

\begin{abstract}
"Na metodologia a gente trabalha muito a parte socioemocional do aluno. Então ele precisa se abrir com a gente, ele precisa falar sobre si, falar seus anseios, suas dúvidas, as suas vontades, quais são as suas metas, os seus objetivos. Então, ele precisa se abrir. Essa parte foi a que eu mais me encantei. (Professora J. B - Núcleo $2^{\circ}$ ano EM).
\end{abstract}

O NTPPS na escola é uma nova forma de dar aula e de estudar. $\mathrm{O}$ aluno é levado a pensar e a falar sobre suas metas, seus projetos, suas vontades, seus medos, suas dúvidas, etc. Veio para construir uma maior relação entre osprofessores e entre professor e aluno, ajudando este a entender como se tornar protagonista da própria vida, desenvolvendo competências e habilidades. E ao professor trouxe a reflexão sobre sua prática, a busca de novos conhecimentos, a querer inovar e a gostar dessa maior aproximação com o aluno.

\begin{abstract}
"Eu lembro de uma aula sobre memória fotográfica, quando eles olham para a foto e começa a aula e a gente começa a falar coisas que façam com que eles retomem aquele momento, aquele passado. Eles veem aquilo ali e começam a se sentir à vontade de falar para você: 'Professora, nessa época aqui, essa foto é de um primo meu, hoje ele já faleceu e ele significava isso, isso e isso na minha vida.' Eles abrem isso para você e eu fico assim, realmente emocionada porque é o que mais me chama atenção no Núcleo, não só a parte da pesquisa, mas, principalmente, essa parte do contato" (Professora J. B $2^{\circ}$ ano Núcleo).
\end{abstract}

"Antes de eu trabalhar no Núcleo, eu ensinava no ensino médio mas dando aula de Geografia (...) eu sempre procurei inovar nas aulas mas me faltava um maior conhecimento para transformar essas aulas em algo mais criativo. O Núcleo veio transformar a mim enquanto educadora" (Professora M.F.C.A - Núcleo $1^{\circ}$ ano EM).

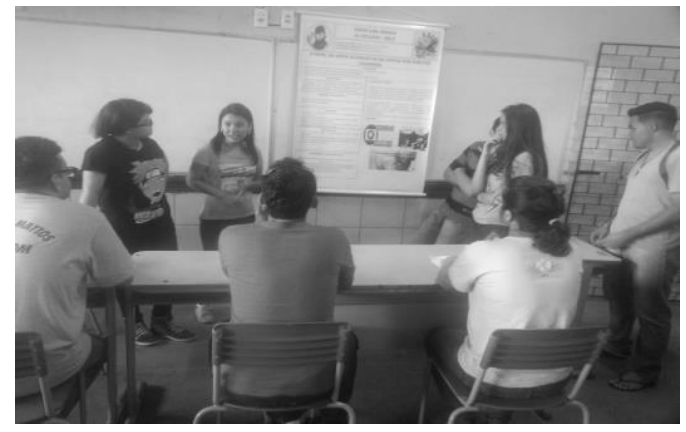

Figura 2. Apresentação dos trabalhos científicos do NTPPS alunos do $1^{\circ}$ ano EM. Fonte: autora

No primeiro ano, o aluno trabalha temas relacionados à escola e a moradia como ambientes de aprendizagem. Desenvolvem nas oficinas, o passo-a-passo de um projeto de pesquisa. E depois aplicam os conhecimentos teóricos na sua própria pesquisa dentro da escola com a ajuda de um professor orientador, produzindo, com os dados, o seu relatório final e apresentando a uma banca composta de três professores, que avaliam e dão sugestões de melhor aperfeiçoamento do trabalho.

No segundo ano os alunos fazem projetos de pesquisa e relatórios de pesquisa que são apresentados por meio de banners. Essa etapa é um pouco diferente pois o objeto de estudo não é mais a escola e sim a comunidade, os alunos 
têm a opção de escolher em que ambiente eles irão trabalhar. Para desenvolver as pesquisas, eles vão às ruas das comunidades onde moram, visitam instituições, conhecem o contexto social em que vivem e se percebem como sujeitos sociais ativos. Trazendo à tona a sua responsabilidade social. Depois esses alunos fazem a "ação" que consiste em mostrar para a comunidade uma resposta da sua pesquisa. Durante a ação alguns grupos trabalham com panfletos, visitas a escolas, hospitais, entidades, sempre realizando uma atividade que possa beneficiar a comunidade estudada.

No $3^{\circ}$ ano há o aprofundamento na maneira de se fazer o projeto, pois nesse ano os alunos já estão próximos a ingressar numa universidade e no mercado de trabalho, e existe uma certa preocupação com o tema, de ser voltado para o mercado de trabalho e a sociedade. Há o incentivo para que o aluno busque conhecer mais as profissões e suas atuações no mercado atual.

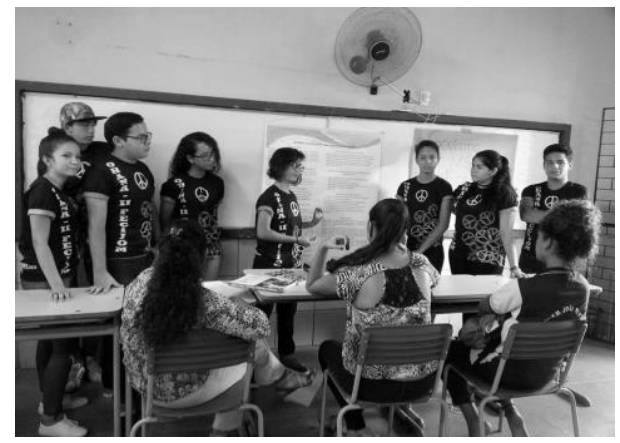

Figura 3. Trabalhos científicos dos alunos do $2^{\circ}$ ano EM. Fonte: autora

\footnotetext{
“ (...) o aluno de primeiro ano ele tem uma noção de pesquisa, que no segundo ano vai sendo aprimorado e no terceiro ano mais ainda. Então a gente ver que os trabalhos de terceiro ano já chegam com um grau de maturidade bem melhor. Em relação aos primeiros anos (...)”. (Professora G.C - Química).
}

"No terceiro ano, também, eu acho que é uma etapa importante por causa da questão de estar voltado para o trabalho. Aqui eles começam a estagiar, já ficam com outro grau de maturidade. Então eu acho que o Núcleo ajudou demais mesmo. (Professora G.C - Química).

$\mathrm{O}$ aluno reconhece a importancia da pesquisa no EM pois ao chegar na faculdade poderá desenvolver trabalhos científicos e esse conhecimento adquirido vai ser muito útil nessa nova fase de sua vida. Como podemos perceber na fala do aluno N.D do $3^{\circ}$ ano da rede pública de ensino: "Talvez em outras escolas a gente fosse para a faculdade sem saber o que é um projeto de pesquisa, um relatório (...) valeu a pena estudar Núcleo.

Depois de cinco anos dessa experiência enriquecedora, que, apesar das dificuldades, tem mostrado resultados positivos, percebe-se como a educação precisa ser reinventada para que a escola seja vista com um espaço prazeroso de vivência e aprendizado significativo.

"O ensino médio, realmente, precisava de uma mudança, devido, historicamente ser uma etapa descaracterizada da educação, pouco valorizada e que os próprios alunos não veem muito sentido naquelas coisas que eles estudam (...) e assim, trazer o aluno para trabalhar em grupo, para aprender a socializar a informação, aprender a pesquisar. Eu achei superimportante, para que ele possa aprender a construir o caminho da aprendizagem dele, para ele ver que a gente produz conhecimento a partir do que os outros pesquisaram, é uma soma de informações, a gente tem que ler, pesquisar, analisar e construir o nosso a partir do que alguém já fez. (Professora G.C - Química).

“ (...) Com o Núcleo na escola você aprende a fazer uma pesquisa e ainda trabalha a sua vida pessoal, suas emoções, suas fraquezas, suas felicidades e se conhece melhor. O Núcleo trabalhou muito isso em mim, na forma de eu conseguir me relacionar bem e saber diferenciar as emoções. Isso é bom tanto para a minha vida pessoal quanto para os meus estudos, para minha vida acadêmica. (Aluna I.K $-2^{\circ}$ ano EM)

De acordo com a Seduc (2017) de uma avaliação realizada em 2015 pelo Instituto Ayrton Senna, o programa de reorganização curricular através da implementação do Núcleo, apresentou resultados médios positivos no que se refere aos domínios de engajamento com o outro, amabilidade e resiliência emocional; beneficiando, principalmente, meninos, alunos com problemas de fluxo, e com baixo desempenho escolar.

Assim, percebe-se que:

O aluno consegue desenvolver o senso crítico e também a competência da pesquisa. Ele busca conhecimento além do que é desenvolvido dentro das disciplinas (...) Muitos tímidos acabam que se sentindo acolhidos no momento das atividades". Cria-se um clima de interatividade, de discussões, de conversas. (Professora R.C - História e Geografia).

Como diria Rubem Alves, é necessário e urgente que a escola crie sonhos. Estes devem ser grandes e importantes, fazendo surgir pessoas de ideias relevantes para o país (Alves, 2001).É importante permitir aos alunos e professores essa oportunidade de sonhar. Perceber que a educação é prazerosa e que a escola é um espaço de harmonia, amizade e conhecimento para a vida; que nela pode-se conversar, chorar, reivindicar, amar e ao mesmo tempo adquirir conhecimento científico, principalmente aquele em que o aluno e o profesor mais gostam e se identificam.

E esse sonhar não parte apenas de um olhar inocente, que enxerga apenas as qualidades do Núcleo. Percebe-se as suas falhas mas busca-se solucionar os problemas pois adimite-se a importância dessa reorganização curricular baseada nas competências socioemocionais dos alunos.Alguns alunos pontuam que não gostam de dinâmicas, que essas aulas participativas são chatas, mas acabam se envolvendo e participando das oficinas normalmente. Em relação à pesquisa, alunos também criticam, dizendo que é muito difícil, mas no final eles realizam aquilo que mais gostam, quer seja na leitura e elaboração de textos ou fichamentos, quer seja na realização de gráficos ou na parte da apresentação.

A maior dificuldade encontrada é relacionada à infraestrutura (computadores e espaços físicos) e a rejeição por parte de alguns professores que ainda não visualizaram a importância da pesquisa e do desenvolvimento de competências socioemocionais dentro da escola.

Observa-se a resistência de alguns professores por ainda não ter esse conhecimento. Tem até o 
conhecimento da proposta, mas a vivência em si é diferente. Quando se vivencia é que de fato se percebe a grande importância de um trabalho como esse. (Professora R.C - História e Geografia).

Uma falha seria na questão de capacitar os professores, pois não deveriam capacitar apenas os professores de Núcleo mas todos os professores pois todos serão orientadores, pois tem professor que não tem noção, assim, do que se passa dentro do Núcleo, não consegue dar um reforço nas pesquisas porque está desvinculado e também não consegue, algumas vezes, orientar trabalhos porque ele mesmo não tem noção do que é pesquisa (...), com uma ajuda acho que o corpo docente ficaria mais apto a produzir mais e melhor. Isso daria visibilidade às escolas, poderia ir para feiras estaduais, publicar trabalhos. Está na hora de pegar essas pesquisas e tornar algo maior, trazer isso como resultado de cada escola, pois no momento em que você dar a visibilidade está dando a chance da escola crescer também" (Professora G.C - Química).

Dessa forma, percebe-se que ainda será preciso um olhar mais cuidadoso sobre o professor orientador. É interessante que não haja julgamento, mas que seja encontrada a solução para esse problema. Uma capacitação continuada poderia ser realizada, para que essa proposta do Núcleo não se perda e se torne apenas mais uma matéria isolada e sem sentido para o aluno e para o professor.

\section{Percurso Metodológico}

Optou-se por fazer uma análise baseada na metodología qualitativa através do método de entrevistas não estruturadascom dez alunos e 5 professores da Escola de Ensino Fundamental e Médio João Mattos, Ceará Brasil. Além da entrevista, também trabalhamos com a técnica da observação, onde os alunos e profesores foram observados nos momentos de aula e de descontração dentro da escola. Os alunos entrevistados foram escolhidos aleatoriamente naescola João Mattos

\section{Conclusão}

Essa proposta de reorganização curricular coloca os alunos como sujeitos ativos e isso desenvolve neles o pensar sobre a sua história de vida, a sua ação enquanto sujeito social. Eles usam o conhecimento para transformar, não só a realidade deles, mas também realidades dentro de suas comunidades, dentro da escola. Isso gera uma modificação no aprendizado do aluno como um todo pois ele passa a ver além da aparência, pois há a possibilidade de enxergar a essência, os porquês, os problemas.

O Núcleo traz essas reflexões para dentro da escola e a partir disso, pode-se obter um jovem atuante na sociedade, consciente das suas atitudes, das suas ações sociais.

\section{Referências}

Alves, R. Entre a ciência e a sapiência: o dilema da educação. $5^{\text {a }}$ edição. São Paulo: Edições Loyola, 2001.

Brasil. Diretrizes Curriculares Nacionais gerais da educação Básica. Brasília: MEC, SEB, DICEI, 2013.
Francelino, E. T. A integração das TIC na reorganização curricular das escolas da rede estadual do Ceará que aderiram ao protótipo de currículo da UNESCO. 2016. 283 p. Dissertação (Mestrado em Ciências daeducação) - Universidade de Trás-os-Montes e Alto Douro. Vila Real, Portugal, 2016.

Instituto Ayrton Senna. Competências para a vida. 2017. Küller, J. A. "Protótipos curriculares de Ensino Médio e Ensino Médio integrado: resumo executivo”. Série

Debates UNESCO 1. 2011.Material de Referência Seminário Internacional Competências para a Vida: onde estamos e aonde queremos chegar? 2017.

Nobre, I.T. A reorganização curricular do ensino médio na rede pública estadual do Ceará: um estudo de caso na EEFM João Mattos.Fortaleza: UFC, 2015. 